Celia Castro Gonsales Profesor Departamento de Arquitectura

y Urbanismo

Universidade Federal de Pelotas

Pelotas, Brazil https://orcid.org/0000-0002-9249-1390 celia.gonsales@gmail.com

Gabriel Alvariz Lopes Graduando em Arquitetura e

Urbanismo

Universidade Federal de Pelotas (UFPEL)

Pelotas, Brazil https://orcid.org/0000-000 I-6726-050X gabriel-lopes@live.com
Forma Aberta:

a proposta de Oskar Hansen e Svein Hatloy para o PREVI - Proyecto Experimental de Vivienda - Peru.

\section{OPEN FORM:}

OSKAR HANSEN AND SVEIN HATLOY'S PROPOSAL FOR PREVI — PROYECTO EXPERIMENTAL DE VIVIENDA - PERU.

FORMA ABIERTA:
LA PROPUESTA DE OSKAR HANSEN Y
SVEIN HATLOY PARA PREVI — PROYECTO
EXPERIMENTAL DE VIVIENDA — PERU.

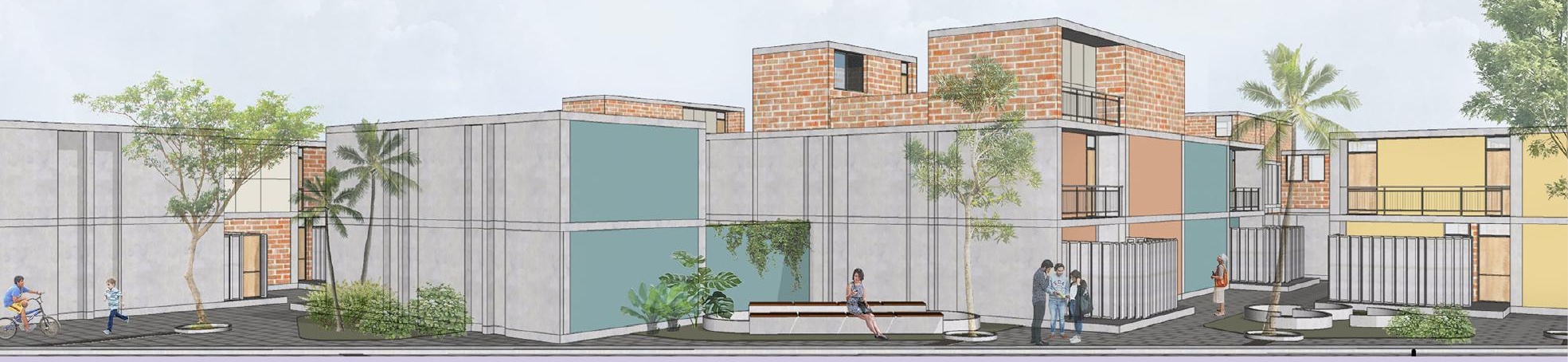

Figura 0 Proposta de Hansen e Hatloy para o PREVI. Espaço urbano como fundo e estrutura para os eventos urbanos, um dos princípios da Forma Aberta. Fonte: produção livre dos autores baseada nos dados fornecidos pelo projeto.
Este artigo é fruto de pesquisa intitulada "Habitação e cidade na segunda metade do século XX: Alternativas à proposta funcionalista na habitação social no contexto iberolatinoamericano", e contou com apoio da Coordenação de Aperfeiçoamento de Pessoal de Nível Superior (CAPES), Brasil — código de financiamento 001 - e da Fundação de Amparo à Pesquisa do Estado do Rio Grande do Sul (FAPERGS), Brasil — bolsa de iniciação científica 


\section{RESUMO}

O concurso para o conjunto habitacional do PREVI (Proyecto Experimental de Vivienda), realizado em 1969, em Lima, se deu em um momento especialmente fértil de reflexões sobre as transformações da arquitetura e, principalmente, das cidades. Nesse contexto de crítica, temas como a participação cidadã e a transformação da arquitetura no tempo tornaram-se centrais e influíram decisivamente nas propostas das 13 equipes internacionais que participaram do concurso no Peru. Esse laboratório projetual, promovido pelo governo peruano com financiamento da $\mathrm{ONU}$, tornou-se, na visão dos autores deste artigo, uma experiência fundamental em habitação social na América Latina no século XX, concentrando projetos seminais cujas ideias reverberam ainda hoje. Se todas as equipes internacionais convidadas a participar do concurso já tinham, naquele momento, um significativo repertório no tema da habitação e estavam em grande sintonia com a produção crítica de seus contemporâneos, a equipe polonesa, composta por Oskar Hansen e Svein Hatloy, trazia para o Peru uma bagagem de trabalho muito particular que vinha desenvolvendo no leste europeu. Dois conceitos estruturantes da produção prática e teórica de Oskar Hansen e de sua esposa, Zofia Hansen — a "Forma Aberta" e o seu desdobramento em escala urbana, o "Sistema Linear Contínuo" (SLC) — aparecem na proposta para o PREVI como instrumentos na busca por uma arquitetura flexível no espaço e no tempo, aberta à participação e intervenção do morador e adequada às suas particularidades socioculturais. Desse modo, o presente artigo tem por objetivo resgatar, em um recorte mais específico, as ideias norteadoras da proposta polonesa para o concurso e, em sentido mais amplo, trazer à tona a importância do PREVI enquanto referência fundamental para projetos de habitação social na contemporaneidade.

Palavras-chave: habitação social, PREVI, revisão do modernismo, Forma Aberta, habitação flexível.

\section{ABSTRACT}

The competition for the housing estate of PREVI (Proyecto Experimental de Vivienda - Experimental Housing Project), carried out in 1969, in Lima, happened in a specially fruitful moment of reflections concerning changes of architecture and, mainly, of the cities. In this context of criticism, issues as the citizen participation and the change of architecture over time became central and influenced decisively in the proposals of 13 international teams that participated in the competition in Peru. This projectual lab, promoted by the Peruvian government with UN funds, became, according to the opinion of the authors of the present article, a fundamental experience in social housing in Latin America in the 20th century, concentrating seminal projects whose ideas still reverberate nowadays. If all international teams invited to participate in the contest already had, at the time, a significant repertoire in the housing issue and had a good understanding with the critical production of their contemporaries, the Polish team, with Oskar Hansen and Svein Hatloy, brought to Peru a very peculiar work experience that they had been developing in Eastern Europe. Two structuring concepts of practical and theoretical practice of Oskar Hansen and his wife, Zofia Hansen — the 'Open Form' and its deployment in urban scale, the 'Linear Continuous System' (LCS) - appear in the proposal for PREVI as instruments in the search for a flexible architecture in space and time, open to participation and intervention of the dweller and adequate to his/her sociocultural peculiarities. Therefore, the present article aims at redeeming, in a more specific clipping, the guiding ideas of the Polish proposal for the contest, and, in a broader sense, raising the importance of PREVI as fundamental reference for social housing projects nowadays.

Keywords: social housing, PREVI, Modernism review, Open Form, flexible housing.

\section{RESUMEN}

El concurso para el conjunto de viviendas PREVI (Proyecto Experimental de Vivienda), realizado en 1969, en Lima, ocurrió en un momento especialmente fértil de reflexiones sobre las transformaciones de la arquitectura y, sobre todo, de las ciudades. En ese contexto de crítica, temas como la participación ciudadana y la transformación de la arquitectura en el tiempo se hicieron centrales. Se trató de un proceso en el cual influyeron decisivamente las propuestas de los 13 equipos internacionales que participaron del concurso en Perú. Ese laboratorio proyectual, promocionado por el gobierno peruano con financiación de la $\mathrm{ONU}$, devino, en la visión de los autores que se exponen en el presente artículo, una experiencia fundamental en vivienda social en Latinoamérica durante el siglo XX, a través de proyectos seminales cuyas ideas reverberan todavía hoy. Si todos los arquitectos invitados a participar del concurso ya tenían, en ese momento, un significativo repertorio en el tema de vivienda y estaban en gran sintonía con la producción crítica de sus contemporáneos, la dupla polaca, compuesta por Oskar Hansen y Svein Hatloy, trajo a Perú una experiencia de trabajo muy particular que se venía desarrollando en el este europeo. Dos conceptos estructurantes de la producción práctica y teórica de Oskar Hansen y su esposa, Zofia Hansen - la "forma abierta" y su desarrollo en escala urbana, el "Sistema Lineal Continuo" (SLC) - se muestran en la propuesta para PREVI como instrumentos para la búsqueda de una arquitectura flexible en el espacio y en el tiempo, abierta a la participación e intervención ciudadana y adecuada a sus singularidades socioculturales. De ese modo, el siguiente documento tiene como objetivo rescatar, mediante un recorte específico, las ideas conductoras del proyecto polaco para el citado concurso y, en sentido más amplio, exponer la importancia de PREVI en cuanto referencia fundamental para proyectos de vivienda social en la contemporaneidad.

Palabras-clave: vivienda social, PREVI, revisión del modernismo, Forma Abierta, vivienda flexible. 

habitat ocupou um espaço destacado no campo da arquitetura e urbanismo na segunda metade do século $X X$, tanto no contexto de reconstrução do Pós-Guerra europeu como no quadro de crescimento bastante desenfreado. das cidades latino-americanas a partir da migração campo-cidade. Nesses dois cenários, questões como a construção e a reconstrução dos centros urbanos, o crescimento populacional, as dificuldades econômicas e o aumento das desigualdades sociais traziam à tona a necessidade de incorporar processos participativos e de autoconstrução nas pesquisas projetuais sobre habitação.

A participação cidadã, por um lado, e as particularidades dos sujeitos sociais, por outro, vão se tornar, então, temas fundamentais que se manifestam em diferentes níveis, seja em uma apreensão mais objetiva e direta — os desejos e as necessidades de cada morador ou de cada familia incidindo sobre o projeto, e dele demandando maior flexibilidade —, seja em uma interpretação mais ampla e indireta — os aspectos culturais, a tradição construtiva vernacular e as urbanizações informais, por exemplo, tomados como referência no ato projetual. As possibilidades de efetivação dessa contribuição, direta ou indireta, do indivíduo ou da coletividade na construção do seu habitat torna-se foco de um campo vasto de investigações metodológicas, pondo em xeque, em alguma medida, o papel tradicional do arquiteto enquanto criador de uma forma definitiva e irretocável.

Nesse contexto participativo - que se inseria em um debate mais geral, dos anos 50 e 60, calcado nas divergências em relação aos dogmas funcionalistas do Movimento Moderno —, trabalhos como os de Giancarlo de Carlo (19192005) e Ralph Erskine (19/4-2005) em habitação social foram centrais. De Carlo, como destaca Farias (2019), previa a inclusão do morador em uma operação arquitetônica que propunha a habitação como um objeto não acabado e que incorporava o tempo e o uso em suas diversas etapas. Por sua vez, Erskine incluiu, no BykerWall (Newcastle-upon-Tyne, Inglaterra, 1973), para citar apenas seu projeto mais importante, a consulta à comunidade local, resultando, como testemunha P. Campos (2017), em um projeto "muito humano" que conecta a comunidade a seu território.

Essas propostas no campo da arquitetura e do urbanismo encontravam paralelo em toda uma "poética da abertura" que, naquele momento, efervescia no campo intelectual e artístico em geral, conforme apontava Umberto Eco em sua Obra Aberta (1962): as composições do alemão Karlheinz Stockhausen, a escrita de James Joyce em Finnegans Wake e os móbiles de Alexander Calder são alguns exemplos que demonstram esse amplo movimento de mudança de paradigma, presente já em décadas anteriores, que passava a considerar um sujeito mais ativo na própria constituição da obra e/ou de suas interpretações $(H$. Campos, 1975; Melo, 2016).

Dentro desse contexto de renovações tão profundas, que reverberaram diretamente em projetos de construção da cidade contemporânea desde o Segundo Pós-Guerra, o Proyecto Experimental de Vivienda (PREVI), realizado no Peru entre 1968 e 1975, pode ser considerado uma das mais importantes experiências com habitação social já realizadas na América Latina. Coincidem, nesse sentido, as perspectivas de Alejandro Aravena e de Kenneth Frampton, que equiparam o PREVI à Weissenhofsiedlung (1927), em Sttutgart, colocando-os como os dois grandes momentos da história da habitação social, por seu caráter 
experimental e grande alcance internacional (Aravena, 2004; Frampton, 20 I5).

O laboratório que se instalou em Lima no concurso para o PREVI, com 4 I projetos apresentados - e entre eles, 13 realizados por algumas das equipes mais renomadas nos anos 60 na Europa, Estados Unidos e Japão - configura um importantíssimo evento de experimentação farta e fértil que pode ser verificado tanto em arquivos e publicações como na Unidade Experimental construída na capital peruana. Estudar com detalhe e extrair dessa riquíssima produção lições de arquitetura e de habitação social pertinentes para a contemporaneidade foram os objetivos de uma ampla investigação empreendida pelos autores, da qual este artigo é procedente.

Uma das equipes participantes do concurso com mais experiência em projetos participativos - e profundamente inserida nesse ambiente de novas propostas no Segundo Pós-Guerra — era a polonesa, composta pelos arquitetos Oskar Hansen (1922-2005), de origem finlandesa e graduado pela Universidade deVarsóvia, e seu pupilo Svein Hatloy (1940-20 I5) (Ruiz Alonso, 20 I8).

Em sua carreira profissional, conciliando arte, arquitetura e docência, Oskar Hansen desenvolveu, junto com sua esposa, a também arquiteta Zofia Hansen (1924-20 I3), o conceito de Forma Aberta, fundamental para entender tanto o legado do casal, quanto o projeto para o PREVI. Esse conceito, apresentado no CIAM de Otterlo, em 1959 (Hansen \& Hansen, 1959), representava o empenho em substituir uma ideia de obra - de arte, de arquitetura e urbana - tradicional, rígida e unívoca, por formas não cristalizadas, abertas no sentido da extensa possibilidade de resultados e da livre reação e atuação do fruidor.

Assim se referia Oskar Hansen ao espaço arquitetônico concebido segundo esse princípio:

Deve absorver as mais variadas funções permanentes (trabalho, alimentação, lazer), bem como funções acidentais, espontâneas — que ocorrem na convivência dos moradores no tempo. [...] Deve enfatizar a individualidade dos habitantes e a escala de seus sentimentos. $\bigcirc$ espaço arquitetônico deve transformar-se ao longo do tempo de uma forma individual para uma forma de multiplicidade e vice-versa. ' (O. Hansen, 1958, p. 436)

A Forma Aberta, como explica López-Marcos (2015), rompendo com uma concepção espacial rígida — própria da forma "fechada" - era proposta como uma espacialidade flexível onde os indivíduos voltavam a ter um papel ativo através de sua capacidade de produção de um espaço reflexivo. Assim, a arquitetura e o urbanismo gerariam um suporte sobre o qual o moradorl habitante poderia, mesmo que como participante de um processo coletivo, ser capaz de perceber, gerar e adaptar seu espaço a partir de suas necessidades.

Oskar e Zofia Hansen aplicaram o conceito de Forma Aberta inicialmente em 1958, no projeto do Conjunto da Cooperativa de Moradias de Varsóvia (WSM Rakowiec), onde desenvolveram uma grande diversidade tipológica de apartamentos, dando oportunidade de escolha aos futuros moradores ( $Z$. Hansen, s.d.).

Mais tarde, o projeto do Conjunto Habitacional Juliusz Slowacki (LSM), em Lublin, de 1961, mostrava um avanço da possibilidade de escolha entre tipos pré-definidos, ensaiada em Rakowiec, para uma "construção que permitia transformações de longo alcance" (Z. Hansen, s.d., para. 33)², com diversos 


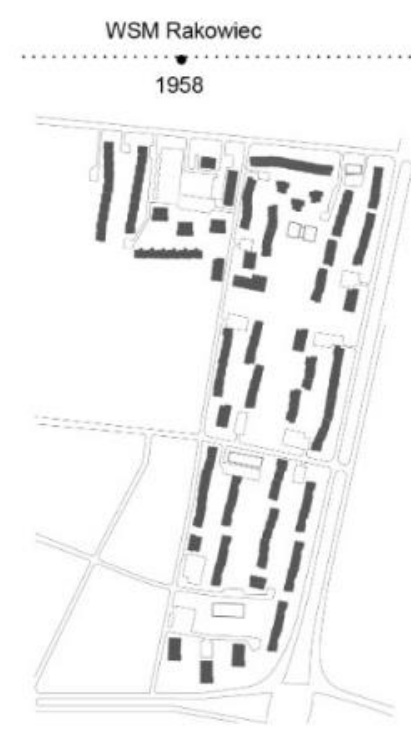

Figura 1 Esquema de implantação de WSM Rakowiec, LSM Slowacki e Przyczólek Grochowski. Fonte: elaborado pelos autores com base nos projetos originais, disponíveis em Hansen Family Archives. (http://www.hansen-family.net/).

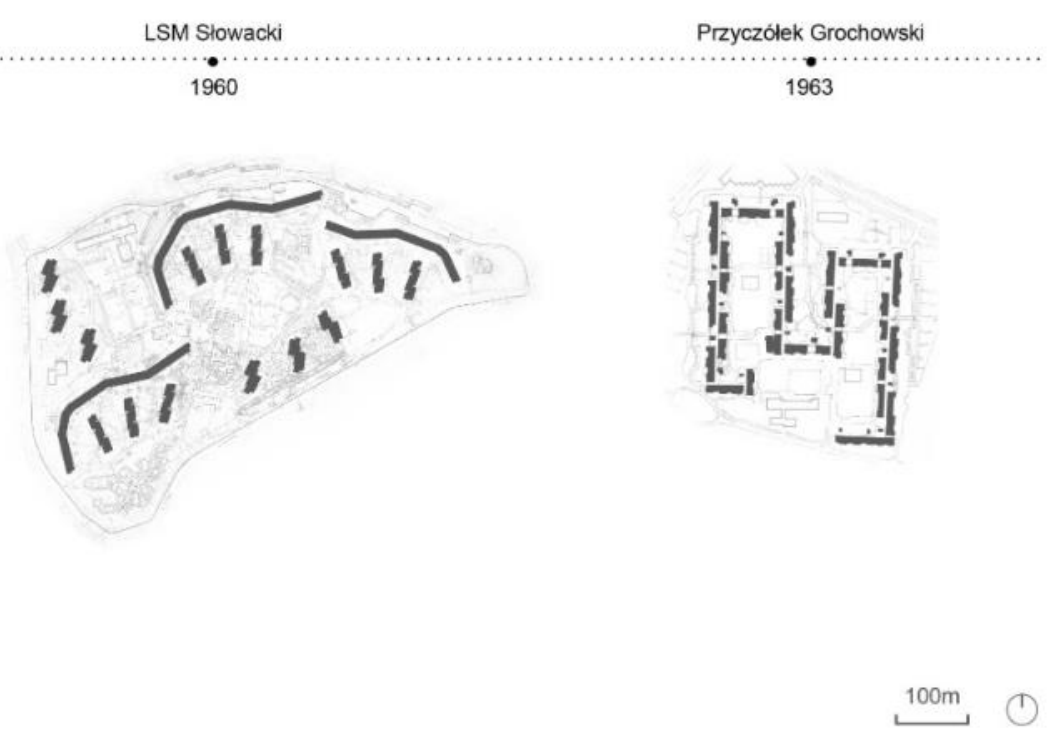

módulos de habitação flexíveis e de dimensões variadas, para famílias de 2 a 5 pessoas. Para cada módulo pré-definido eram desenvolvidas diversas possibilidades de organização interna, apresentadas na forma de questionário aos moradores, que tinham, ainda, a autonomia para elaborar a sua própria proposta (López-Marcos, 20 I5; Stanek, 20 I4). Uma estrutura independente pré-fabricada dava conta da flexibilidade do projeto, incluindo, por exemplo, vigas com esperas para a instalação das sacadas, acopladas à fachada de acordo com a organização interna definida para o apartamento.

Em 1963 o casal inicia o projeto do conjunto Przyczólek Grochowski, em Varsóvia, com blocos sustentados por um sistema pré-fabricado de pórticos transversais que permitia arranjos flexíveis, incluindo futuras junções de apartamentos adjacentes mediante a supressão de fechamentos internos. A galeria, de 1,5 km, que ligava os blocos, foi pensada como um vetor de encontro entre os moradores e sua configuração "dobrada" conformava áreas livres protegidas para lazer e para a localização de equipamentos como escola primária, jardim de infância, enfermaria e administração (Kedziorek \& Stanek, 20 I2).

Todas estas experiências de habitação (Figura I) constituíam ensaios de um modo de viver em comunidade que os arquitetos julgavam compatível com o regime socialista da Polônia e que por este seria oportunizado (cf. Stanek, 20 I4; Springer, 2017).

Essa pesquisa constante com organizações lineares, em que a circulação adquiria uma importância crescente como elemento estrutural-espacial, constitui uma experimentação em escala reduzida do Sistema Linear Contínuo - SLC (Linear Continuous System - LCS), princípio que os Hansen estavam desenvolvendo nesse momento. Esse sistema, que propunha uma nova forma de assentamento urbano no território polonês, consistia em um arranjo em faixas funcionais paralelas que intercalavam proporcionalmente zonas servidoras e servidas, dando aos indivíduos, através da mobilidade transversal e longitudinal, oportunidade equitativa de acesso aos equipamentos públicos e à vida urbana de modo geral. Ao romper com as tradicionais e hierárquicas formas urbanas 


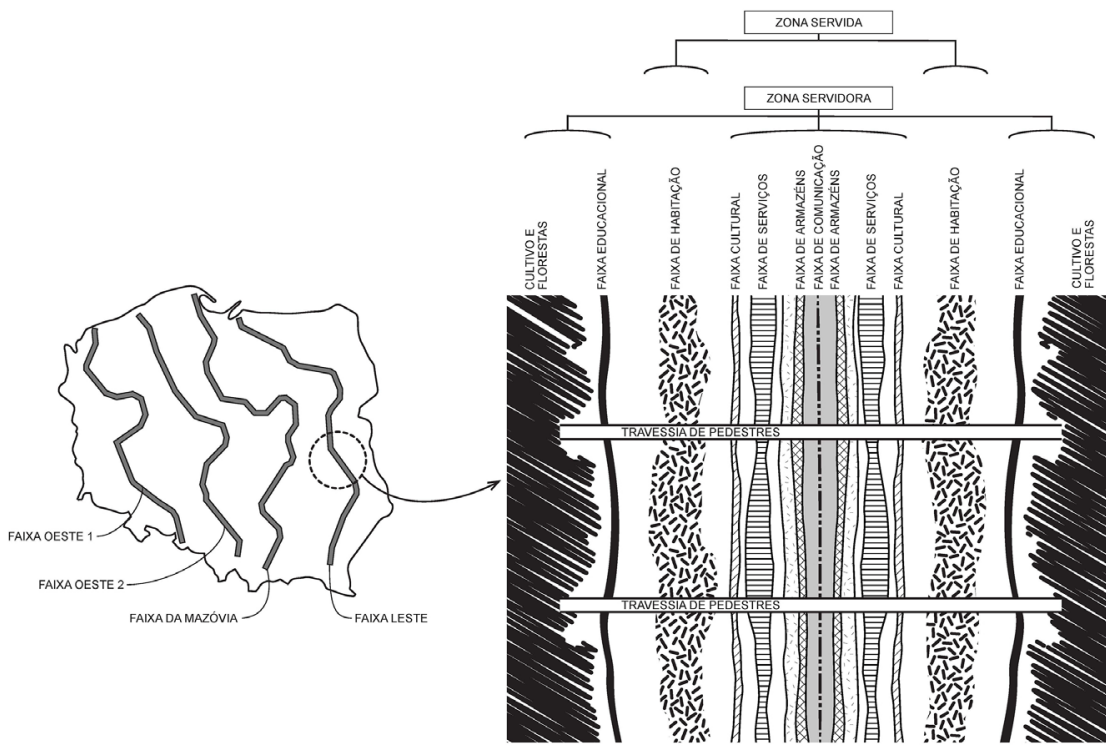

centralizadas - com crescimento diametral periférico em relação a uma região central fixa —, no SLC, graças ao arranjo linear, habitação e serviços manteriam uma relação equilibrada, mesmo com a expansão da urbanização $(O$. Hansen, 1969; Kwiatkowski, 2019).

Assim, Hansen aplicava a ideia da Forma Aberta a uma dimensão infinitamente maior, regional: quatro faixas desse sistema cruzariam toda a Polônia, ligando o centro demográfico europeu ao mar (Figura 2). Nessas faixas, a interpretação da Forma Aberta se traduzia em uma ideia de cidade que se constituía essencialmente como infraestrutura, um suporte sobre o qual os moradores estariam providos das funções urbanas básicas e teriam liberdade para constituir seu habitat. Desenhos e maquetes de aproximação da chamada Faixa Oeste I, por exemplo, mostravam uma estrutura escalonada, como uma colossal arquibancada contínua, em que os habitantes construiriam suas moradias. ${ }^{3}$ O SLC se coadunava, então, com as megaestruturas propostas no mesmo período - por exemplo, pelos metabolistas japoneses - e que tinham como referência primordial o Plano Obus (1931), de Le Corbusier (Banham, 2020). Nesses projetos, uma grande estrutura servia de base para unidades menores, com ciclo de vida mais curto e passíveis de substituição (residências, edifícios etc.), constituindo um sistema expansível e flexível.

O SLC conformaria, assim, a base para uma sociedade mais igualitária, aproximando "os aspectos positivos da cidade, ou seja, os confortos da civilização, e os aspectos positivos do campo, ou seja, o contato mais próximo com a natureza" (Hansen, 1969, p. 2). ${ }^{4}$

Nessa mesma época, a trajetória dos Hansen no tema da habitação social, desenvolvida sob os conceitos aqui expostos, culminaria no convite do arquiteto britânico Peter Land para participação no concurso para uma grande urbanização de habitação social a ser implantada em Lima, Peru, dentro do programa PREVI. Nesta ocasião, Oskar esteve acompanhado do jovem colega Svein Hatloy (1940-20I5), arquiteto norueguês que desde 1965 estava na Polônia colaborando com os Hansen.
Figura 2 Esquema do SLC cruzando a Polônia, à esquerda, e aproximação detalhada, à direita

Fonte: elaborado pelos autores com base em material disponível em Hansen Family Archives (http://www.hansen-family.net/).
3 Imagens disponíveis em http://www.hansen-family. net/ (Oskar - Concepts - LCS western 1) 
5 O PREVI consistia, a princípio, em três projetos-piloto: PP1, projeto de uma urbanização; PP2, melhoramento de áreas existentes; e PP3, apoio à autoconstrução de habitação e equipamentos. Posteriormente, foi incorporado o PP4, com o objetivo de reconstruir as áreas afetadas pelo terremoto de 1970 (Land, 2008).

6 As equipes convidadas eram: Kiyonori Kikutake, Fumihiko Maki, Kisho Kurokawa (Japão); Christopher Alexander (EUA); Toivo Konhonem (Finlândia); Rafael Esguerra García, Álvaro Sáenz Camacho, Germán Samper Gnecco e Rafael Urdaneta Holguín (Colômbia); Knud Svenssons (Dinamarca); Hansen e Hatloy (Polônia); Herbert Ohl (Alemanha); Atelier 5 (Suíça); Iñiguez de Onzoño e Vázquez de Castro (Espanha); Georges Candilis, Alexis Josic e Shadrack Woods (França); James Stirling (Inglaterra); Aldo Van Eyck (Holanda) e Charles Correa (Índia) ("PREVI/Lima", 1970; Land, 2008).
Proyecto Experimental de Vivienda (PREVI), gerido pelo governo do arquiteto Fernando Belaúnde Terry e financiado pelo PNUD (Programa das Nações Unidas para o Desenvolvimento) no final da década de 1960, foi uma proposta desenvolvida no marco da vertiginosa migração do campo para as cidades costeiras, em especial para Lima, que provocou um déficit habitacional, à semelhança de outros centros urbanos latino-americanos, com a proliferação de diversos assentamentos irregulares e precários em sua periferia.

Com a intenção de ser um grande laboratório para o tema da habitação na América Latina, o PREVI era composto por vários programas, entre eles o $\mathrm{PPI}{ }^{\mathbf{5}}$, que previa a construção de um novo bairro com 1500 unidades residenciais e, para tal, a realização do referido concurso, em 1969. Deste participaram 28 equipes peruanas - concurso aberto - e 13 equipes internacionais concurso por convite ${ }^{6}$ (Gonsales \& Bertinetti, 2019).

Os arquitetos que compunham as equipes internacionais estavam, de alguma forma, inseridos no contexto de crítica ao dogmatismo da cidade funcionalista, alguns inclusive participando do núcleo do Team X (como Aldo Van Eyck e o grupo Candillis, Josic e Woods) e outros orbitando o seu milieu (como Hansen, a equipe japonesa e James Stirling). Não por acaso, o edital do concurso tinha grande sintonia com os novos paradigmas que surgiam a partir dessa produção crítica - que englobava todo o cenário crítico construído pelos Situacionistas, por Jane Jacobs, pelo próprio Cristopher Alexander, participante do concurso, entre tantos outros - , e considerava em alto grau as peculiaridades socioculturais e geográficas do Peru e a viabilidade econômica e tecnológica do projeto.

Entre requisitos obrigatórios e recomendações do concurso, as equipes deveriam observar parâmetros como o caráter flexível e evolutivo das residências e crescimento por fases, dando margem à participação das familias na conformação progressiva do seu habitat e levando em consideração os arranjos familiares peruanos. Em escala urbana destacava-se, por exemplo, a necessidade de alta densidade aliada à baixa altura, além da prioridade de percurso de pedestres, com espaços abertos polivalentes - a interpretação de espaços abertos tradicionais no Peru, como plazas e paseos, era incentivada ("PREVI/ Lima", 1970).

O concurso habitacional do PREVI constituiu, assim, um grande campo experimental em que arquitetos dos hemisférios norte e sul puderam testar ou ampliar investigações que vinham realizando com habitação, na conjuntura da crítica ao "espaço abstrato e universal" da matriz funcionalista, e que inclúa uma abordagem mais contextualista do projeto e a ideia de um sujeito mais atuante.

As coincidências das bases conceituais e ideológicas postas no PREVI com os preceitos dos arquitetos procedentes da Polônia vão configurar o concurso no Peru como uma oportunidade ímpar de aplicação, por parte de Hansen e Hatloy, da teoria da Forma Aberta e do Sistema Linear Contínuo. Este artigo tem como objetivo o estudo do projeto de Hansen e Hatloy para o concurso PREVI, desvelando os conceitos e procedimentos contidos em seu interior, resgatando sua espacialidade e tentando trazer à tona um experimento que, por sua complexidade e maturidade, comporta um rol de investigações ainda muito maior.

Nesse sentido, os cadernos do Ministerio de la Vivienda del Peru (ININVI, 197I), onde estão publicados os projetos do concurso PREVI e seus memoriais, 


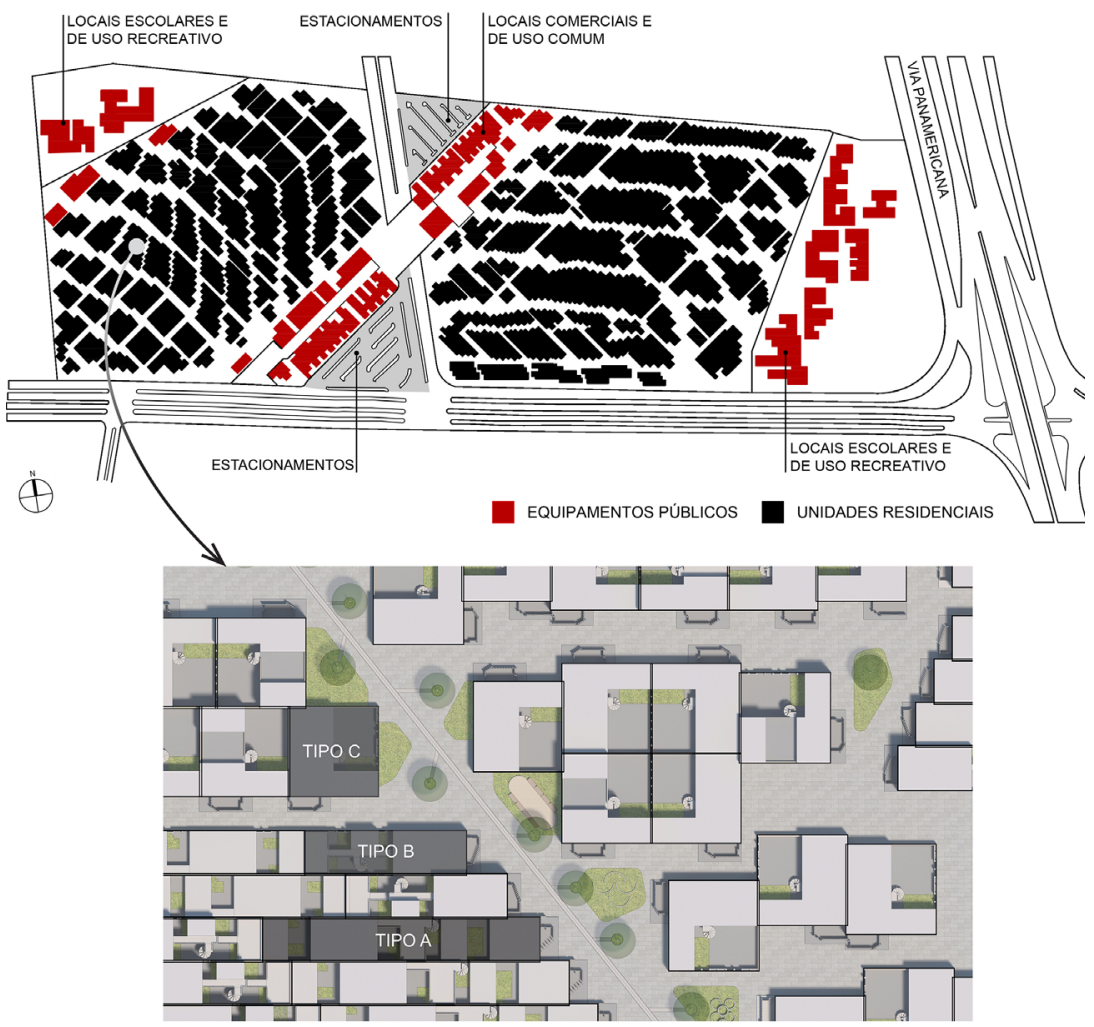

Figura 3 Projeto urbano geral: domínio público e privado. Fonte: redesenho dos autores a partir de imagens disponíveis em ININVI \& Ministerio de Vivienda (1971, v. 18).

assim como a mais recente publicação The Experimental Housing Project (PREVI), Lima, (LAND, 20 I5), de autoria do próprio Peter Land, um amplo catálogo das propostas para o PPI, são fontes essenciais deste estudo. Por outro lado, o acesso ao arquivo da familia Hansen (http://www.hansen-family.net/) foi fundamental para completar as informações sobre o projeto de Hansen e Hatloy já presentes nas referências bibliográficas citadas acima.

\section{A escala da cidade: o Sistema Linear Contínuo}

terreno designado para o concurso possuía uma área de 40 hectares, encontrava-se na região de expansão ao norte de Lima, junto à rodovia Panamericana, e fazia parte de uma área residencial dez vezes maior, para a qual o conjunto poderia se expandir posteriormente ("PREVI/Lima", 1970).

arranjo proposto pela equipe polonesa alude ao Sistema Linear Contínuo e o projeto como um todo é um exercício de aplicação direta da Forma Aberta. Uma faixa central de comércio, serviços e equipamentos, que atua como espinha dorsal do conjunto, aparece diagonal no terreno, obedecendo à direção dos ventos predominantes de sudoeste a nordeste e canalizando-os através de cinturões de vegetação. ${ }^{7}$ Nas extremidades leste e oeste do conjunto, complementando as áreas servidoras da faixa central segundo a seção transversal proposta no SLC, localizam-se duas zonas de atividades escolares e recreativas com áreas verdes, promovendo certo isolamento do conjunto em relação às vias de tráfego intenso, sobretudo à Pan-Americana.

Entre essas áreas de equipamentos públicos encontram-se as duas grandes faixas residenciais do conjunto (Figura 3). Nelas, as unidades habitacionais de diferentes tipos se associam em parcelas de diversos tamanhos que, a partir de

7 As pranchas originais do projeto podem ser consultadas na íntegra em http://www. hansen-family.net/ (Oskar Projects - Housing, aba "UN Previ"), arquivo que conta com diversos diagramas explicativos acerca da proposta e é a base para grande parte das informações que serão apresentadas no decorrer deste trabalho. 
uma trama geométrica bastante livre, vão formando o espaço urbano; desse modo, a implantação seria progressiva e comportaria alguma flexibilidade. A proposta de residências geminadas proporcionaria já uma densidade elevada ao conjunto - se considerarmos a altura máxima de três pavimentos alcançando uma média de 250 hab/ha (Ininvi \& Ministerio de Vivienda, 197I, v. 18), mas que poderia quase dobrar com a ampliação das residências ao longo do tempo.

A proposta PREVI como uma seção transversal de um arranjo linear (SLC) expõe o movimento do dia-a-dia dos habitantes: moradia, serviços, produção/trabalho, lazer e contato com a natureza. Essa organização implica que essas faixas poderiam facilmente se estender à medida que o conjunto se expandisse, demonstrando grande abertura — no léxico de Hansen — do conjunto e um potencial sempre latente de conexão com o entorno. Por outro lado, a associação bastante livre entre unidades gera caminhos diversos e pouco rígidos que conectam o eixo central e as zonas laterais de recreação, fazendo com que haja um fluxo transversal constante e diverso de pessoas ao longo do dia, potencializando os contatos sociais.

Os diagramas apresentados pelos arquitetos demonstravam uma organização orientada para o pedestre, com raio máximo de 10 minutos de caminhada dos moradores até equipamentos e espaços comuns, assim como às vias rápidas de conexão com o restante da cidade. $\bigcirc$ automóvel chega somente aos bolsões de estacionamento, localizados nos extremos dessa faixa central, junto às vias de automóvel. A via existente que cruza o terreno transversalmente passa pelo "eixo servidor" de maneira subterrânea, facilitando a caminhada do morador por todo o conjunto.

No conjunto estão propostos vários níveis de agrupamentos. Os pátios internos das residências, que correspondem aos espaços privados, são a primeira instância de lugar de encontro, de reunião e de lazer, muito especialmente para as crianças. Por outro lado, o desenho das ruas para pedestres, com suas reentrâncias e pequenos locais de estar e brincar, valoriza a leitura de intimidade e caracteriza esses espaços "semiprivados" enquanto extensões do lar, fomentando pequenas coletividades e a relação entre vizinhos, através de um espaço público conector mensurável e particularizado. Nesses potenciais lugares de convivência estariam áreas de lazer multietário, plantações e alguma infraestrutura, como canteiros e drenagem.

Essas ruelas de infiltração no conjunto desembocam em espaços abertos mais amplos, de caráter público, associados aos equipamentos no centro e bordas do terreno. Esse posicionamento, ao mesmo tempo que afasta do tráfego de veículos a habitação, abre o conjunto para o entorno. A relação dos diferentes espaços abertos é uma das traduções do que foi pensado como lugar de "relações sociais" pelos arquitetos:

As áreas abertas em torno das habitações conferem uma grande variedade de caminhos para os pedestres, assim como lugares para que as crianças brinquem próximo a suas casas. Esses caminhos são compostos por áreas privadas abertas e são conectadas pela zona central de serviço e também pelas laterais de recreação. As condições criadas são favoráveis para o estabelecimento de contatos sociais variados ("PREVI/Lima", I 970, p. 200). ${ }^{8}$ 

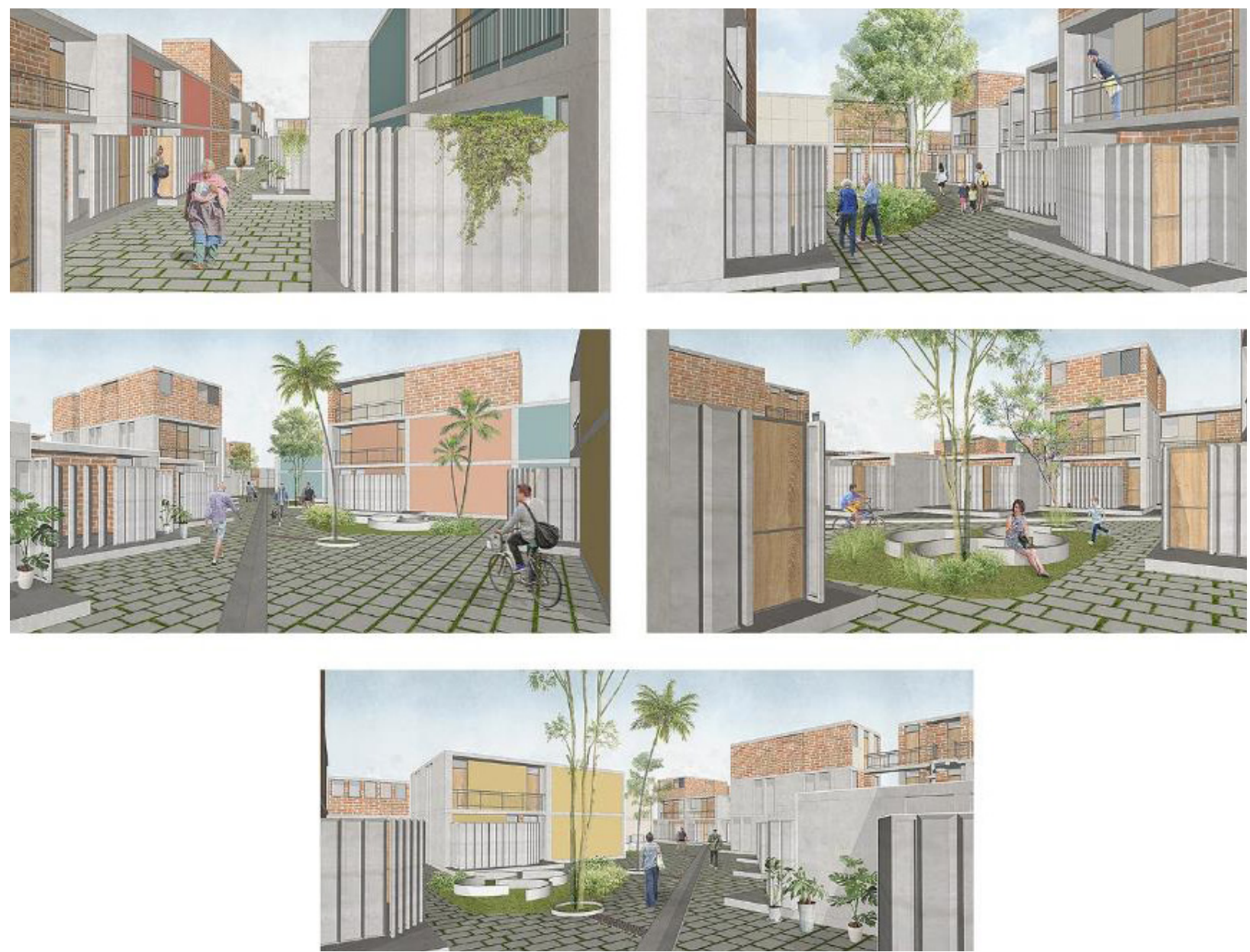

Mediante a articulação entre essas diversas categorias de espaços abertos, repetindo estratégias utilizadas nos conjuntos Juliusz Slowacki e Przyczólek Grochowski, os arquitetos previram as atividades gerais de acordo com as diferentes faixas etárias e com distâncias adequadas até a casa: no primeiro grupo, as crianças de até 3 anos de idade ficariam acompanhadas dos pais, utilizando os espaços abertos no interior da residência. $O$ segundo grupo, de 3 a 6 anos, já teria autonomia para brincar no playground, que estaria num raio de $30 \mathrm{~m}$ de cada habitação, geralmente localizado nas diversas reentrâncias geradas no espaço urbano através de deslocamentos das edificações. $O$ último grupo abrange as crianças dos 6 aos 14 anos que seriam capazes de ir a clubes e áreas de esportes, que estão localizadas a até $500 \mathrm{~m}$ das residências. Esse cuidado com a adequação do projeto aos diversos grupos etários de crianças demonstra uma tentativa de promover desde cedo a apropriação progressiva e segura dos espaços coletivos.

O conceito de arquitetura como suporte - que vinha sendo trabalhado pelos arquitetos - está claramente explorado neste projeto, a partir de uma proposta de espaço urbano com limites claros e configuração apreensível, onde os elementos físicos atuam como um fundo continuado que destaca as figuras - pessoas e atividades - ao mesmo tempo que as vincula (Figura 4). ${ }^{9}$
Figura 4 Ospaço urbano. Fonte: produção livre dos autores baseada nos dados fornecidos pelo projeto.
9 ompendo com as estratégias básicas do urbanismo moderno - sobretudo aquele consolidado nos CIAMs de Entreguerras e na Carta de Atenas (1933) - , que põe os elementos físicos - a arquitetura - como figuras contra um fundo espacial infinito e amorfo. 
Figura 5 Unidade residencial: elementos construtivos e arranjos tipológicos. Fonte: produção dos autores baseada nos dados fornecidos pelo projeto.

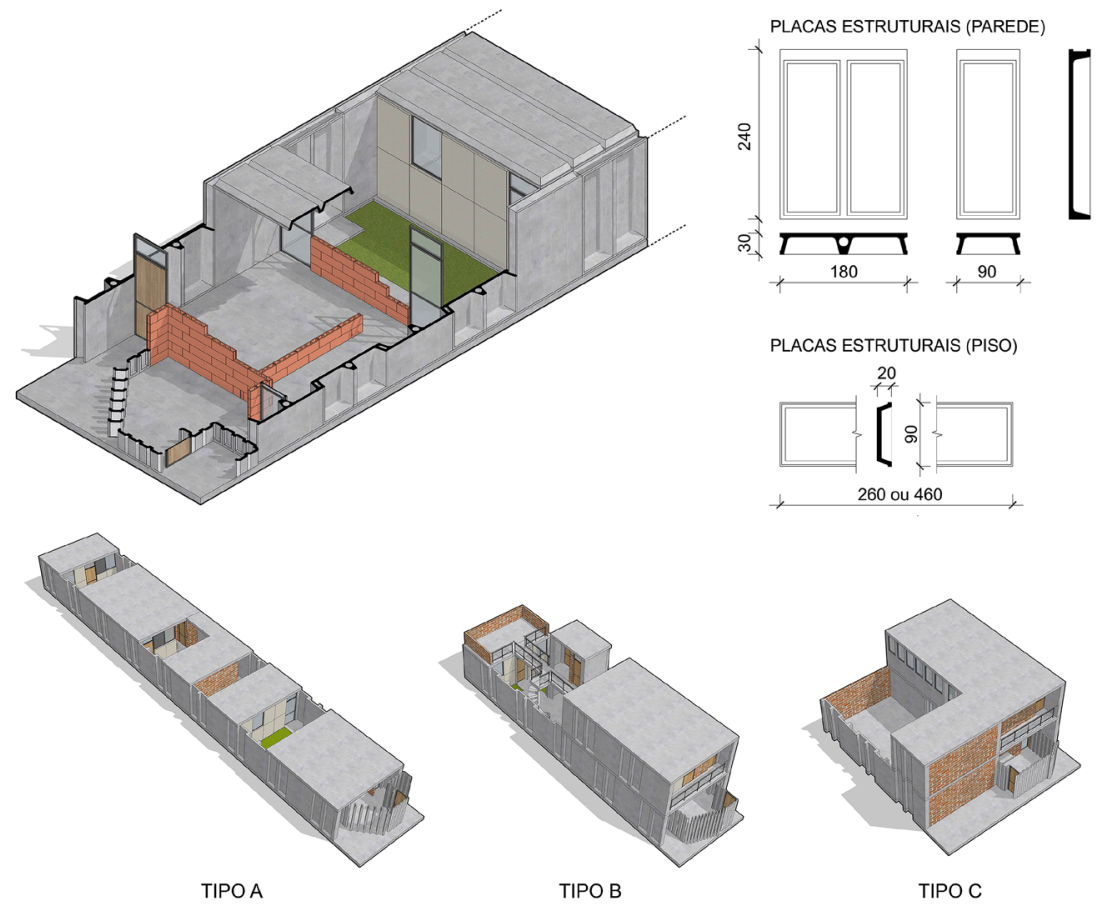

\section{A escala da unidade residencial: a Forma Aberta}

Se o PREVI não previa uma participação direta do futuro morador nas fases iniciais do projeto, a diversidade possível de dimensões e organizações internas das habitações, como veremos, pressupunha uma intervenção deste em fases posteriores de ocupação de sua moradia.

Os experimentos de Oskar Hansen com a participação do morador no complemento de sua casa servem de base para o PREVI, agora com o tema da moradia unifamiliar. Um sistema construtivo pré-fabricado em concreto compõe o fechamento perimetral do lote e as lajes de entrepiso e cobertura. Nas etapas posteriores, fechamentos com blocos cerâmicos ou de concreto, painéis, esquadrias, divisórias com tecido etc. possibilitariam a execução pelos próprios moradores de acordo com suas necessidades de uso e possibilidades econômicas (Figura 5). A estratégia de utilizar elementos de construção mais pesados para definir os limites do lote permite, a partir desse "suporte", grande flexibilidade interna - demonstrando uma preocupação simultânea com os princípios da Forma Aberta e com a integridade da espacialidade urbana.

Assim, três tipos gerais de unidades (A, B - lote alongado, e C - lote compacto) com diversos subtipos, a partir da variação de profundidade do lote, são propostos, produzindo uma extensa gama de possibilidades de arranjos para a habitação.

O projeto na escala da residência buscava contemplar as diferentes composições familiares peruanas, especialmente as polinucleares. A coabitação era uma situação recorrente e as expansões da casa deveriam responder a esse desenvolvimento familiar ao longo do tempo. Desse modo, a residência base abrigava um primeiro núcleo familiar e, à medida que a família crescesse e os filhos formassem novos núcleos, a moradia permitia expansões com certa 

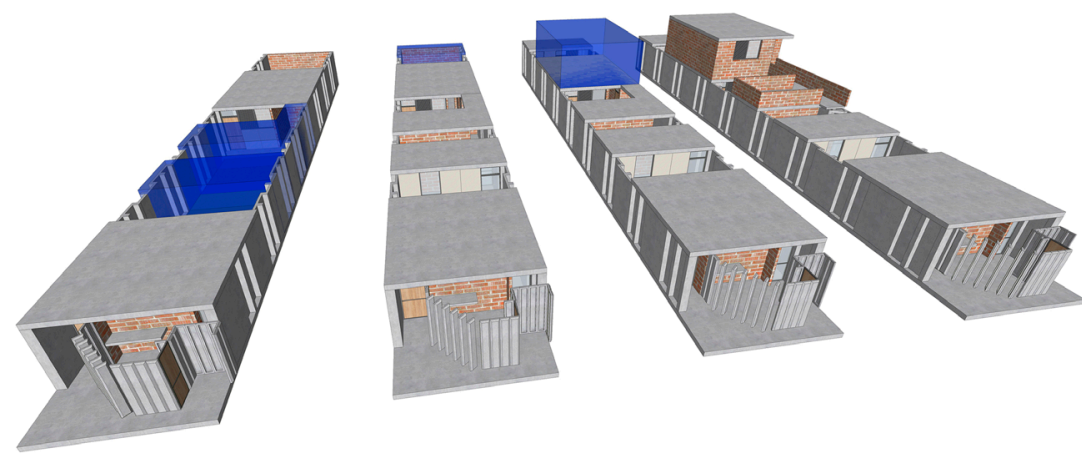

Figura 6 Unidade residencial, tipo A: processo de ampliação; setorização e fluxos. Fonte: produção dos autores baseada nos dados fornecidos pelo projeto.

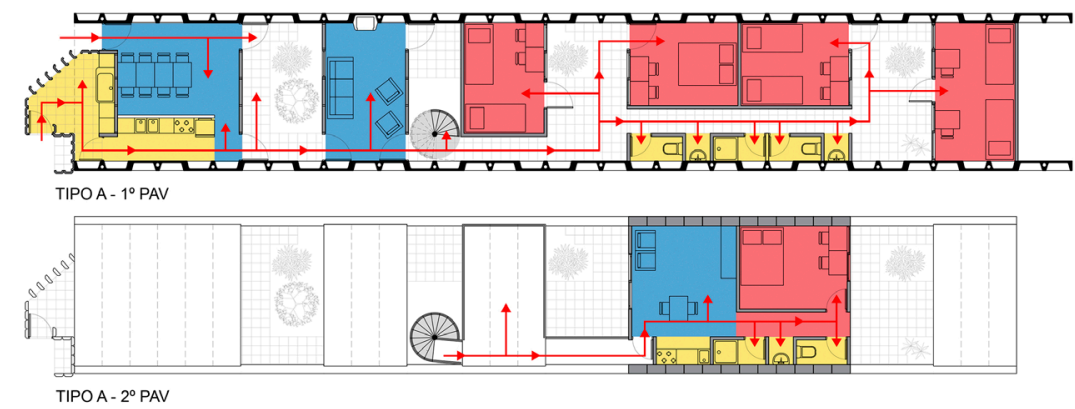

$\square$ ÁREA SOCIAL $\square$ ÁREA INTIMA $\square$ AREA SERVIÇO $\square$ CIRCULAÇÃO VERTICAL — ACESSOS E FLUXOS

autonomia funcional dos espaços.

No tipo A, bastante alongado, a intercalação dos espaços construídos e seus pátios privativos encontra na estrutura do perímetro a sugestão de modulação para o crescimento futuro, visando uma boa relação entre ambiente fechado e aberto, com dimensões apropriadas de pátio para insolação e ventilação natural. Essa organização gera uma gradação de privacidade bastante clara, desde os ambientes mais sociais, na entrada, até os mais íntimos, ao fundo. Em princípio, este tipo abrigaria no máximo dois pavimentos, sendo o superior - equipado com cozinha própria, banheiro, sala e dormitório - reservado para um segundo núcleo familiar (Figura 6).

No tipo B, menos profundo que o anterior, um único pátio central separa, no térreo, o setor social e um dormitório. Entre esses volumes estão os banheiros e a circulação vertical. No pavimento superior, uma passarela articula as três áreas da planta — dormitórios, banheiros e terraço - e atua como cobertura para a circulação no térreo. Este tipo e o anterior abrigariam até dois núcleos familiares, chegando ao total de oito a nove pessoas, respectivamente (Figura 7).

Já o tipo $C$ tem no térreo espaços mais definidos e, no segundo pavimento, a possibilidade de remanejo espacial no interior de uma casca previamente constituída. Este tipo comportaria 3 pavimentos com possibilidade, então, de abrigar até 3 núcleos familiares e um total de doze pessoas (Figura 8).

Os três tipos têm soluções funcionais em comum, como a demarcação da área de serviço externa, por onde se dá o acesso secundário. Se o posicionamento frontal do setor de serviço afasta a residência do contato direto com a rua, tornando a casa mais introspectiva, os pátios se tornam 
Figura 7 Unidade residencial, tipo B: proposta de ampliação; setorização e fluxos. Fonte: produção dos autores baseada nos dados fornecidos pelo projeto.
Figura 8 Unidade residencial, tipo C: proposta de ampliação; setorização e fluxos. Fonte: produção dos autores baseada nos dados fornecidos pelo projeto.
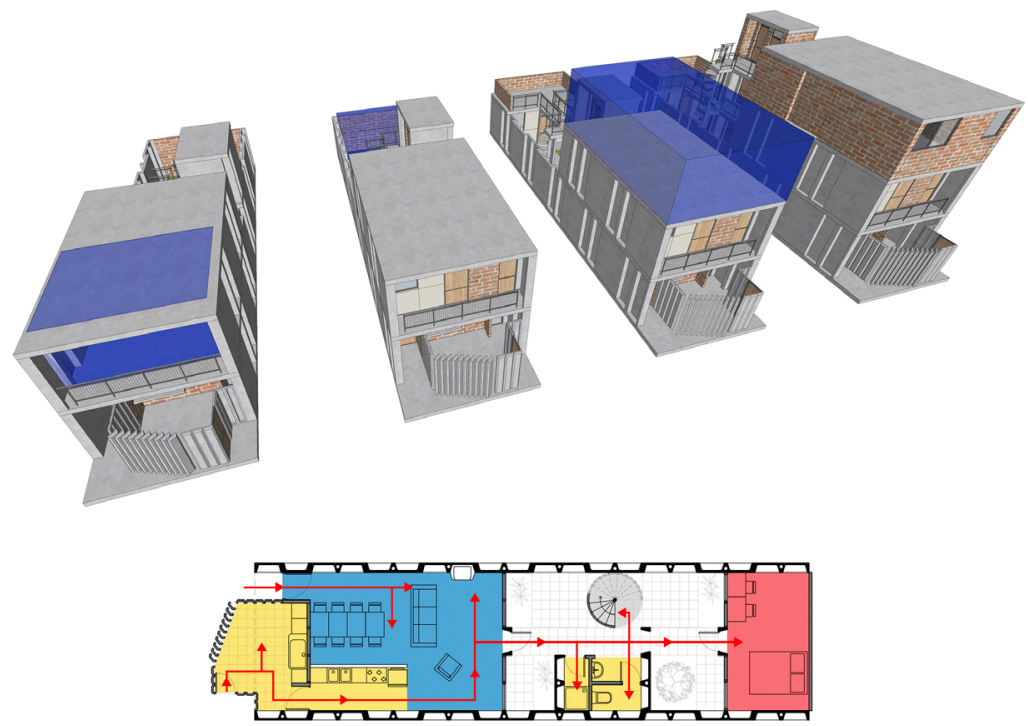

TIPO B - $1^{\circ}$ PAV

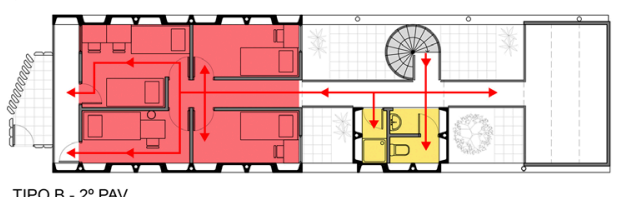

TIPO B - 2 ${ }^{\circ}$ PAV

$\square$ ÁREA SOCIAL $\square$ ÁREA INTIMA $\square$ ÁREA SERVIÇO $\square$ CIRCULAÇÃO VERTICAL — ACESSOS E FLUXOS
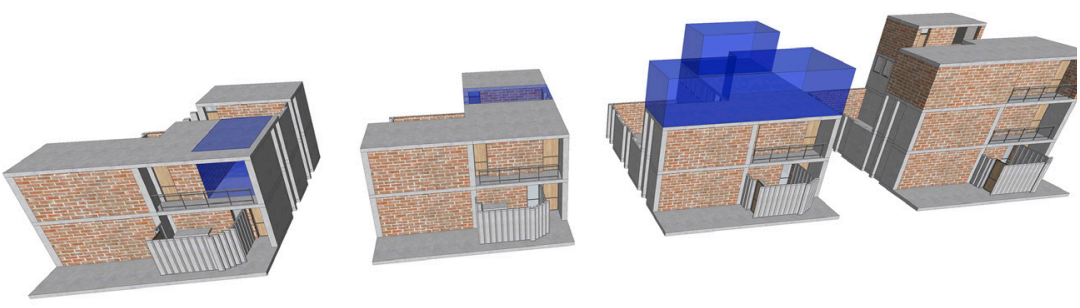

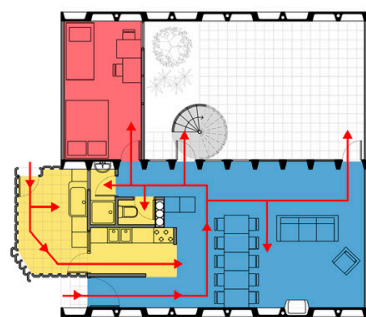

TIPO C - $1^{\circ}$ PAV
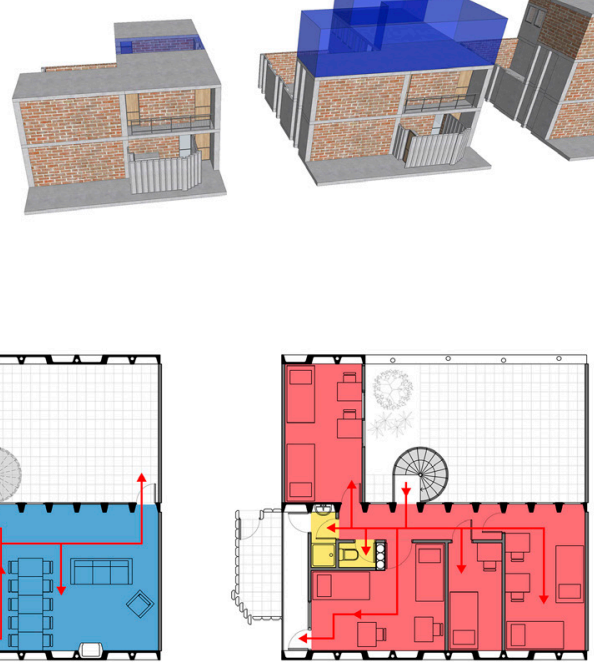

TIPO C - $2^{\circ}$ PAV $\square$ ÁREA SOCIAL $\square$ ÁREA INTIMA $\square$ ÁREA SERVIÇO $\square$ CIRCULAÇÃO VERTICAL — ACESSOS E FLUXOS

então instrumentos fundamentais para a sensação de extensão dos ambientes internos.

Assim, por serem originados a partir de uma mesma lógica construtiva e compartilharem de algumas soluções formais/funcionais, os diversos tipos de habitação coexistem e se articulam gerando um conjunto com linguagem bastante coesa, apesar da alta complexidade e até mesmo imprevisibilidade de sua implantação. 
A proposta de Oskar Hansen e Svein Hatloy para o PREVI evidencia uma dialética constante entre repetição e mudança, regra e liberdade individual, suporte rígido e Forma Aberta, na qual o papel do arquiteto é essencialmente diferente daquele baseado no projeto de uma forma final, da qual se tem controle absoluto. Nesse projeto, a forma espacial assume caráter de processo, o projeto é um substrato que dá margem a novas possibilidades.

Essa redução no grau de determinação do projeto não significa, necessariamente, uma simplificação ou redução do papel do arquiteto, senão, talvez, uma maior complexidade, evidenciada, no caso em estudo, pelas diversas variações tipológicas, possibilidades de crescimento e adequação a arranjos familiares distintos, uso de diferentes materiais de construção e previsão para ocupação progressiva do espaço. A capacidade de flexibilidade do projeto diante desses fatores é aliada a um certo controle dos projetistas sobre a forma, seja arquitetônica ou urbana, e, portanto, sobre a qualidade ambiental dos espaços, buscando uma relação qualificada entre a rigidez do suporte e a liberdade dada aos moradores.

O esforço em adaptar uma proposta tão universal como o SLC (cujos esquemas mostravam a possibilidade de expansão para todo o continente europeu) às idiossincrasias do Peru lança luz sobre a grande complexidade que envolvia o trabalho dos arquitetos do Pós-Guerra, os da chamada terceira geração, vinculados às discussões de revisão e crítica no interior do próprio Movimento Moderno.

Por um lado, o "homem universal" da primeira fase do modernismo transformava-se em indivíduo específico - " "sujeito antes do objeto", nos termos de Hatloy —, à medida que se cristalizava uma abordagem cada vez mais sociológica do pensamento sobre a cidade. Categorias como identidade, comunidade e associação, marcantes no trabalho de Alison (1928-1993) e Peter Smithson (1923-2003), para citar dois arquitetos com investigações alinhadas às de Hansen, contrapunham-se claramente às categorias funcionais da Carta de Atenas, evidenciando desde o princípio dos anos 1950 a mudança de paradigma em curso. Em contrapartida, não raramente essa mesma geração de arquitetos, que buscava nas experiências reais e locais um sentido de lugar, debruçava-se sobre conceitos de planejamento e projeto cuja matriz era ainda essencialmente universal e totalizadora - com foco, é claro, em dar solução prática e eficiente às vulnerabilidades de um mundo chacoalhado pela guerra e em vertiginoso crescimento populacional e urbano.

Assim, conceitos urbanos em voga nesse momento, como as propostas megaestruturalistas ou até a ideia de mat-building — que refletiram nas proposições teóricas e projetuais de Hansen e, de certo modo, no seu projeto com Hatloy para Lima —, carregavam em si algo de uma contradição interna: se os aspectos locais eram tomados como referência e a liberdade de atuação do indivíduo na constituição do seu habitat era uma premissa fundamental, esta seria alcançada através de elementos estruturais de grande dimensão e avançada tecnologia, e que impunham uma ordem contundente e, em certo sentido, rígida. A liberdade do habitante estaria, portanto, condicionada a uma matriz estrutural cuja construção demandaria força e consenso coletivos, em um processo de intermediação aparentemente difícil entre duas escalas diametralmente opostas, a da megaestrutura e a da habitação espontânea e autóctone.

Por outro lado, nessas propostas estava incorporada também uma nova noção de temporalidade e de flexibilidade da qual o LCS e a Forma Aberta estavam imbuídos: a grande estrutura ordenadora da forma deveria ser capaz de adaptação, transformação e crescimento ao longo do tempo. Dado esse contexto 
de rica complexidade, torna-se especialmente interessante, então, o projeto da equipe polonesa para o PREVI e o exercício mais geral nele contido, qual seja, o de tradução e viabilização de um repertório como o do SLC — desenvolvido essencialmente enquanto proposição teórica e em uma escala territorial muito ampla — no particular contexto periférico peruano, em um conjunto de residências unifamiliares tão diferente dos grandes blocos propostos no leste europeu. A constituição da estrutura-suporte se manifesta, no PREVI, em uma escala menos abrangente, sobretudo na habitação, mas também através dos equipamentos públicos e infraestrutura urbana básica, que possibilitariam alguma flexibilidade na implantação geral do conjunto e facilitariam sua expansão.

Pautado, justamente, na tensão entre o universal e o local, o tecnológico e o autóctone, o planejamento e a contingência, o projeto de Hansen e Hatloy exprime com eloquência o debate sobre arquitetura e cidade de seu tempo. A forma final de outrora entra em franca dissolução, bem representada pela dicotomia hanseniana entre forma fechada e Forma Aberta ${ }^{\mathbf{1 0}}$, torna-se processual e flexível, e é atravessada por agentes que, por mais que sempre tenham atuado sobre a arquitetura, não tinham, até então, tanto protagonismo no discurso e na prática hegemônicos: o tempo, a mudança — nos arranjos sociais ou familiares, nos desejos dos usuários etc. —, a liberdade de escolha, a participação da população; em suma, a abertura ao imprevisível e mutável.

\section{REFERÊNCIAS BIBLIOGRÁFICAS}

$10 \mathrm{O}$ ensaio que Hansen e Hatloy realizaram em 1969 no Peru não pôde ser aferido em sua globalidade. O que foi construído a partir deste concurso foi uma Unidade Experimental com 500 unidades onde se reuniu, como em um mostruário, as propostas de 24 equipes participantes, internacionais e peruanas, adaptadas a um projeto urbano realizado por Peter Land.
Aravena, A. (2004). Elemental: building innovative social housing in Chile. Harvard Design Magazine (2I).

Banham, R. (2020). Megastructure: urban futures of the recent past. Monacelli Press.

Campos, H. de (1 975). A obra de arte aberta. In A. de Campos, D. Pignatari, \& H. de Campos, Teoria da poesia concreta:Textos críticos e manifestos: 1950-1960 (2a ed., pp. 30-33). Livraria Duas Cidades. [Texto publicado originalmente no Diário de São Paulo, 03 julho 1955]

Campos, P. F. de (2017). O usuário como protagonista e agente de projeto: das cooperativas de habitação uruguaias ao "Byker Wall" de Newcastle [Conferência]. $4^{\circ}$ Congresso Internacional da Habitação no Espaço Lusófono - CIHEL 2017 (Vol. I), Covilhã, Portugal. https://bit.ly/31944IJ

Farias, A. (2019). A arquitetura da participação de Giancarlo de Carlo revisitada. VIRUS, 18. https://bit.ly/3DcRR28

Frampton, K. (20I5). Preface. In P. Land, The experimental housing Project (PREVI), Lima. Design and Technology in a new neighborhood (pp. 19-21). Universidad de los Andes.

Gonsales, C., \& Bertinetti, G. (20|9). O projeto de habitação e de cidade de Candilis, Josic e Woods para a América do Sul: Proyecto Experimental de ViviendaPrevi, Peru. OCULUM ENSAIOS, I 6(3), 48 I-501. https://doi.org/ 0.24220/23 I 8$0919 v 16 n 3 a 4279$

Hansen, O. ( 1958, Listopad). Studium i realizacja mieszkania. Architektura (I I), 433-440. https://bit.ly/319dEBR 
Hansen, O. (1969). Proposition pour un système d'urbanisme linéaire. Le Carré Bleu (2). https://bit.ly/3FrWN5t

Hansen, O., \& Hansen, Z. (1959). The Open Form in architecture: The art of the great number [Apresentação em Congresso]. CIAM '59, Otterlo, Países Baixos. https://bit.ly/3A4kMna

Hanzen, Z. (s.d.). Joanna Mytkowska rozmawia w Szuminie z Zofią Hansen [Entrevista a Joanna Mytkowska]. https://bit.ly/3BdLZVP

ININVI \& Ministerio De Vivienda. ( 197I). PREVI PP I: I- I O:Vol. I 8. Lima: Ministerio de Vivienda y Construcción del Perú.

Kedziorek, A., \& Stanek, L. (20I2). Architecture as a pedagogical object: What to preserve of the Przyczolek Grochowski Housing Estate by Oskar \& Zofia Hansen in Warsaw?. Architektúra \& urbanizmus, 46(3-4), 250-269. https://bit.ly/3uFR8DI

Kwiatkowski, K. (2019, November). Applications of Linear Systems in Contemporary Urban Design. In IOP Conference Series: Earth and Environmental Science, 362 ( I), 012170 . https://bit.ly/2WDUVoo

Melo,V. P. de (2016). A obra de arte aberta e os processos de interatividade. Revista Interdisciplinar Internacional de Artes Visuais-Art\&Sensorium, 3 ( I), 5 I-6I. https://bit.ly/3uNcr6s

Land, P. (2008). El Proyecto Experimental de Vivienda (PREVI) de Lima: antecedentes e ideas. In F. G. Huidobro, D. Torres, \& N. Tugas, ;El tiempo construye! / Time Builds! (pp. 10-25). Gustavo Gili.

Land, P. (20 I5). The experimental housing Project (PREVI), Lima. Design and Technology in a new neighborhood. Universidad de los Andes.

López-Marcos, M. (20I5). Anti-ciudad como infraestructura. El sistema lineal continuo de Oskar Hansen. Proyecto, Progreso, Arquitectura, 13, 45-57. https://bit. ly/3D8bNmX

Lucas Alonso, P. (20I5). El concurso del tiempo. Las viviendas progresivas del PREVI-Lima. [Tesis doctoral, Universidad Politécnica de Madrid]. https://bit.ly/3a5jCgz

PREVI/Lima: low cost housing project. (1970, April). Architectural Design, 40(4), 187-205.

Ruiz Alonso, J. J. (2018). Oskar Hansen y la forma abierta: influencias e interrelaciones en el desarrollo del arte contemporáneo. Museo Patio Herreriano de Arte Contemporáneo Español. https://bit.ly/3A9UkbQ

Springer, F. (2017). Zlé urodzone: reportaże o architekturze PRL-u. Karakter.

Stanek, L. (20|4). Oskar and Zofia Hansen: Me, You, Us and the State. In L. Stanek (Ed.), Team 10 East: revisionist architecture in real existing modernism (pp. 210 24I). Museum of Modern Art in Warsaw. https://bit.ly/3Fs I 7ld 